\title{
A Novel Approach to Synthesize Helix Wave Hollow Fiber Membranes for Separation Applications
}

\author{
Sung Ryul Park ${ }^{1,2,3}$, Jeong-Hoon $\mathrm{Kim}^{1,2,{ }^{*}}$, Aamer Ali $^{4,5,{ }^{*}}$, Francesca Macedonio ${ }^{4,5}$ and \\ Enrico Drioli ${ }^{4,5,6,7}$
}

${ }^{1}$ Korea Research Institute of Chemical Technology (KRICT), Center for Membranes, 141 Gajeong-Ro, Yuseong-Gu, Daejeon 305-600, Korea

${ }^{2}$ University of Science and Technology, Department of Green Chemistry and Environmental Biotechnology, 217 Gajeong-ro Yuseong-gu, Daejeon 305-350, Korea

${ }^{3}$ Korea Evaluation Institute of Industrial Technology (KEIT), KEIT 1-5F, 32, Cheomdan-Ro 8-Gil, Dong-Gu, Daegu 701-300, Korea

${ }^{4}$ National Research Council - Institute on Membrane Technology (ITM-CNR), Via Pietro BUCCI, c/o The University of Calabria, cubo 17C, 87036 Rende CS, Italy

${ }^{5}$ The University of Calabria - Department of Chemical Engineering and Materials, cubo 44A, Via Pietro BUCCI, 87036 Rende CS, Italy

${ }^{6}$ Hanyang University, WCU Energy Engineering Department, Room 917 9th Floor FTC BIdg., 17 Haengdangdong, Seongdong-gu, Seoul 133-791 S. Korea

${ }^{7} K A U$ - CEDT, Jeddah, $S A$

\begin{abstract}
Helix wave hollow fiber membranes are promising candidate to mitigate fouling and polarization effects in membrane operations. Current study describes a novel but simple approach to synthesize hollow fiber membranes with helix wave configuration. Poly(ether sulfone) (PES) based helix-waved hollow fiber membranes have been fabricated by dry-wet phase inversion process by using asymmetric coagulation conditions. Frequencies of the wave cycle have been observed approximately 20 and the wave length $7.1-7.6 \mathrm{~mm}$ under the specifically required operating conditions defined by dope solution extrudate rate of $1 \mathrm{~g} / \mathrm{min}$ through $4 \mathrm{~cm}$ of air-gap heights with $8.6 \mathrm{~m} / \mathrm{min}$ of winding speeds. On the other hand, simple hollow fibers are formed when the elongation force exerted by the winder is much higher than the surface tension of the external coagulant. The process can be useful for making polymer fibers for other applications as well.
\end{abstract}

Keywords: Helix wave, hollow fiber membranes, poly (ether sulfone), asymmetric coagulation.

\section{INTRODUCTION}

Membrane operations are playing a vibrant role in numerous applications including desalination, wastewater treatment, gas separation, energy sector, food and beverage industry and several other associated industrial segments. Main advantages of membrane processes include their less energy intensive and environmental friendly nature, easy to scale up, well controlled interactions at molecular scale and wide range of separation achievable [1]. However further growth and widespread adoption of membrane processes has been related with successfully addressing the operational key issues such as fouling and concentration polarization (CP).

*Address correspondence to these authors at the National Research Council Institute on Membrane Technology (ITM-CNR), Via Pietro BUCCI, c/o The University of Calabria, cubo 17C, 87036 Rende CS, Italy;

Tel: +39-3890020234; Fax: +39-0984402103;

E-mail: amir_hmmad@hotmail.com

Korea Research Institute of Chemical Technology, Center for Membranes, P.O BOX 107, 141 Gajeong-ro, Yuseong-gu, Daejeon 305-600, Korea; Tel: 82-42860-7513; Mob: 82-10-9822-4388; Fax: 82-42-860-7042

E-mail: jhoonkim@krict.re.kr
To control CP and fouling in conventional low pressure membrane processes, several techniques have been practiced [2], however, most of these techniques are complex and expensive to realize. An easy way to control polarization effects in membrane processes is based on the generation of secondary flows inside the membrane modules. The secondary flows direct the foulants away from the membrane surface and promote more homogeneous distribution of fluid inside the module. Undulation of fibers offers one of the most convenient approaches to generate secondary flows inside the fibers. Twisted, curly, helical and wavy configurations have been applied to realize the formation of secondary flows in membrane operations and interesting outcomes have been observed [3-6].

In thermal driven membrane processes such as membrane distillation, membrane crystallization and membrane driers, thermal polarization has been acknowledged as the counterpart of concentration polarization in pressure driven membrane processes 
Table 1: Some Examples of Undulated Membrane Geometries Used for Membrane Separation Processes

\begin{tabular}{|c|c|c|c|}
\hline Fiber's configuration & Application & Formation method & Ref. \\
\hline Wavy & Membrane distillation & Thermal treatment & {$[5]$} \\
\hline $\begin{array}{l}\text { Curly, space knitted, central } \\
\text { tubing modules }\end{array}$ & Membrane distillation & Thermal treatment & [13] \\
\hline Wavy crimped & Oxygenator & Thermal crimping & [18] \\
\hline Wavy & $\begin{array}{l}\text { Purification of aqueous } \\
\text { suspensions }\end{array}$ & $\begin{array}{l}\text { Application of pulsating flow to } \\
\text { nascent fibers before cooling }\end{array}$ & [19] \\
\hline Wavy & $\begin{array}{l}\text { Membrane separation } \\
\text { applications }\end{array}$ & Use of rotating gears & [20] \\
\hline Wavy & Dialyzer & n.m & [15] \\
\hline Wavy & Dialyzer & Thermal treatment & [16] \\
\hline Wavy & Dialyzer & n.m & [21] \\
\hline Gear Shaped and wavy & Membrane distillation & Theoretical study & [22] \\
\hline
\end{tabular}

n.m: Not mentioned.

[7]. To improve thermal polarization coefficient in membrane distillation, various approaches have been tried including the use of baffles, spacers, inserts and particular geometries that make the temperature distribution more homogeneous inside the module [811]. These conventional techniques, however, involve the complexity of incorporation of an external element into the module. Use of secondary flows generated through undulating geometries has been found very effective and easy to incorporate to mitigate the thermal polarization effect in these operations [5, 1214]. Similarly, the benefits of wavy fiber geometry have been well explored in dialysis applications too [15-17].

Table 1 summarizes some examples of formation and use of undulating geometries reported in various studies. Although significant interest exists in application of undulated geometries in various membrane operations, yet the formation of wavy shaped fiber has been reported onlyin a few studies Furthermore, as illustrated in Table 1, the traditional methods to prepare wavy shape fibers include an additional step of post treatment or process modification. Current study provides a general technique for making the helix-wave shaped hollow fibers without introducing any additional process modification or post treatment step. The objective of current short communication is to provide the general proof of the concept of preparing fibers with crimped geometries by using state-of-the-art non solvent induced phase separation technique. The fabricated fibers can be potentially interesting solution to mitigate concentration and thermal polarization in conventional and emerging membrane operations.

\section{EXPERIMENTAL}

\subsection{Materials}

Polyethersulfone powder (PES, 4100P) purchased from Sumitomo Chemical Co., Ltd. was dried for 6 hours at $140{ }^{\circ} \mathrm{C}$ to remove moistures following the recommendation of manufacturers. 1-methyl-2pyrrolidone (NMP, $>99.5 \%$, Sigma Aldrich) and Acetone (>99.5\%, Sigma Aldrich) were used as strong solvent and non-solvent additive, respectively. PES/NMP/Acetone solutions were mixed by mechanical stirrer for 24 hours at $35^{\circ} \mathrm{Cin}$ an oil bath. Dope solution was sealed in the polymer reservoir for 24 hours to degasifyit. Inner coagulant comprised of $80 \%$ NMP and $20 \%$ pure water. A spinning nozzle with $560 \mu \mathrm{m}$ and $280 \mu \mathrm{m}$ of outer and inner diameters respectively, was used to form hollow fibers by simultaneous extrusion of inner coagulant and dope solution. Water circulation was applied to maintain the temperature of the spinneret at $35^{\circ} \mathrm{C}$. Tap water was used as coagulant (strong non-solvent) in the coagulation and quenching baths.

\subsection{Spinning Process}

Hollow fiber spinning was carried out at air-gap distances varying from $0 \mathrm{~cm}$ to $4 \mathrm{~cm}$. Dry-wet phase inversion processes were adapted to fabricate wavy shape asymmetric hollow fiber membranes. Humidity and temperatures of first two coagulation baths were fixed at $30 \%$ and $10^{\circ} \mathrm{C}$, respectively. Figure 1 shows schematic diagram of hollow fiber spinning processes. Flow rates of dope solution and bore fluid were controlled by the gear and the liquid-chromatography 


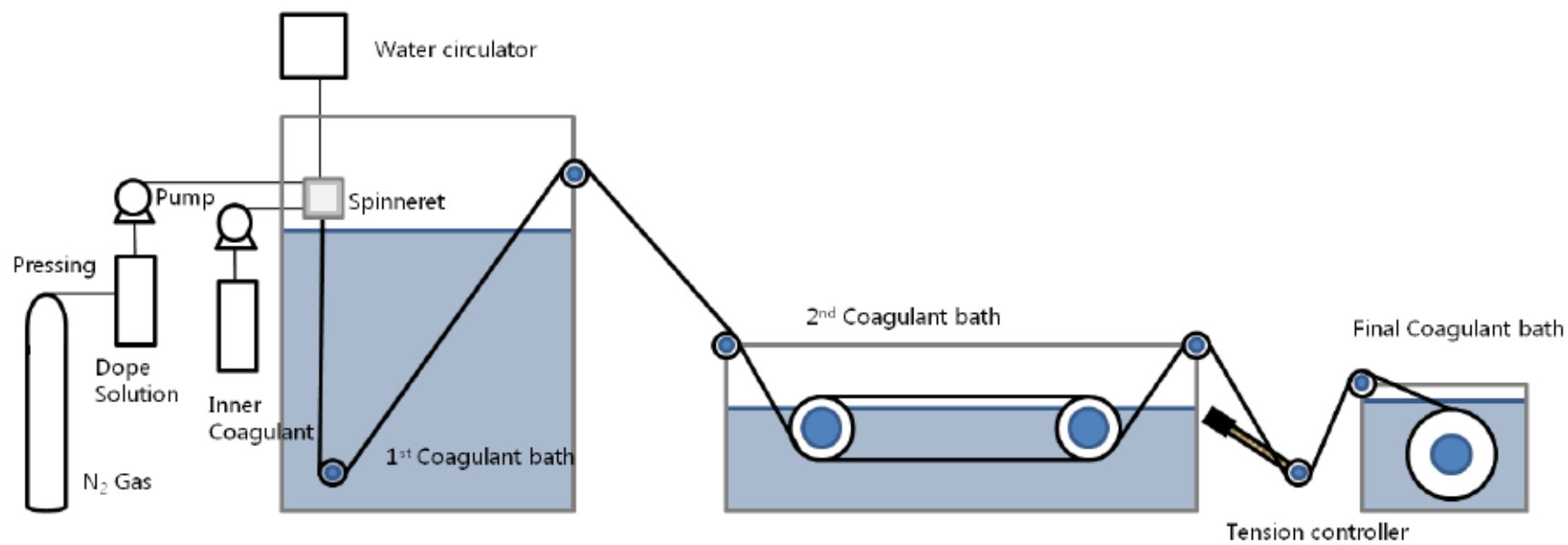

Figure 1: Schematic diagram of spinning processes of hollow fiber membranes. Dope solution is compressed by $\mathrm{N}_{2}$ gas under 5atmpressure. Dope and inner coagulant are supplied regularly by precision pumps. The temperature of spinneret is controlled by the water circulation. Hollow fibers are taken up on the final coagulant bath after passing through the tension controller without cutting.

pump, respectively. Spinning conditions applied have been listed in Table 2. Quenching process was performed in 3 steps in three separate coagulation baths. In order to ensure the removal of residual solvent, the temperature of $3^{\text {rd }}$ bath was controlled at $25^{\circ} \mathrm{C}$ as recommended in the literature [23].

Table 2: Spinning Conditions of PES Hollow Fibers

\begin{tabular}{|c|c|}
\hline Spinning condition & Values \\
\hline \hline Polymer flow rate & $1.0 \mathrm{~g} / \mathrm{min}$ \\
\hline Bore fluid flow rate & $0.32 \mathrm{~g} / \mathrm{min}$ \\
\hline Bore fluid composition & $80 / 20(\mathrm{NMP} /$ Water, wt $\%)$ \\
\hline Spinneret temperature & $35^{\circ} \mathrm{C}$ \\
\hline $\begin{array}{c}\text { Coagulation bath temperature }\left(1^{\text {st }},\right. \\
\left.2^{\text {nd }}, 3^{\text {rd }}\right)\end{array}$ & $10^{\circ} \mathrm{C}, 10^{\circ} \mathrm{C}, 25^{\circ} \mathrm{C}$ \\
\hline Air-gap distance & $0-4 \mathrm{~cm}$ \\
\hline Humidity & $30 \%$ \\
\hline Temperature & $25^{\circ} \mathrm{C}$ \\
\hline Take-up speed & Varied \\
\hline Final coagulation bath temperature & $25^{\circ} \mathrm{C}$ \\
\hline
\end{tabular}

\section{RESULT AND DISCUSSION}

\subsection{Process Description}

The process of making wavy shaped helix fiber resembles with the modified Maxwell model [24], when the equilibrium state between surface tension and axial forces is established. The mechanical responses of viscoelastic materials such as polymers can be interpreted by Maxwell Model which is based on an element comprising of a spring and a dashpot connected in series. The spring and dashpot are used to describe the elastic and viscous behavior of polymer chain, respectively. A schematic of Maxwell model has been shown in of Figure $\mathbf{2} \mathbf{a}$ and the corresponding analogy established in the current work has been illustrated in Figure 2b.

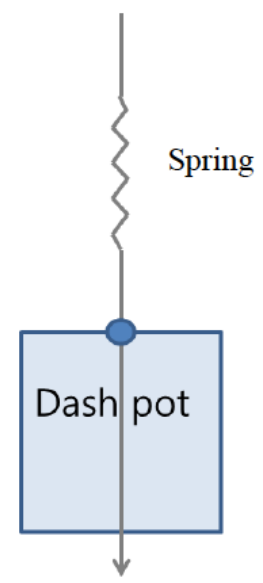

(a)

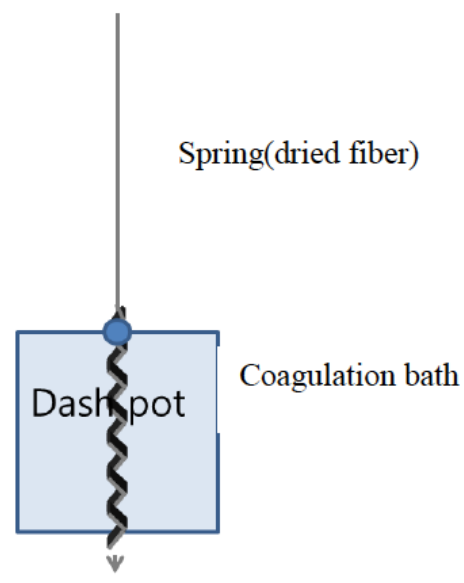

(b)
Figure 2: Schematic diagram of (a) modified Maxwell model (b) Analogy to modified Maxwell model used to fabricate helix wave hollow fibers in the current study.

Mathematical description of spring and dashpot can be written as

$\eta_{E}=\tau E$ For spring

$\gamma(t)=\frac{\sigma_{o}}{\eta} t$ For dashpot

In the Maxwell element, $\mathrm{E}$ the instantaneous tensile modulus, characterizes the response of the spring 


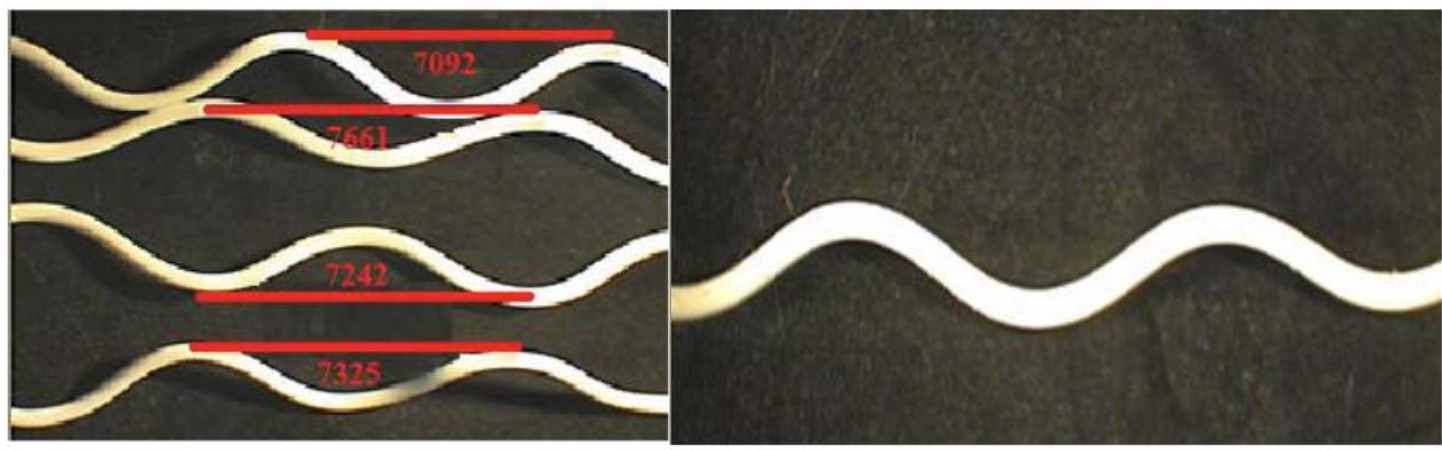

(a)

(b)

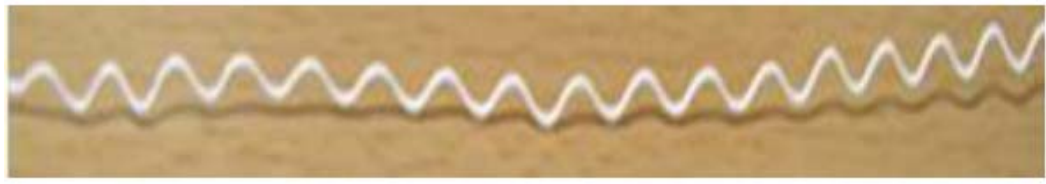

(c)

Figure 3: Different images of the wavy shaped fibers prepared (a) Enlarged image illustrating different wave lengths in microns (b) Image of a single Helix-Wave hollow fiber (c) Side view of Helix-Waved hollow fibers.

while $\eta$, the viscosity of the liquid in the dashpot, defines the viscous behavior. The coagulation bath mimics the dash pot while the fiber formed acts as the spring. During the winding process, the force would first act on the spring (solid fiber) and would be dissipated during working against the surface tension of the coagulant fluid to sink the extruded dope into the coagulation bath.

Different images of fibers obtained have been shown in Figure 3. Drawing speed has been identified as the most crucial parameter for forming wavy shapes under fixed conditions such as composition of dope solution, air-gap distance, extrusion rate and subsequent spinning conditions. The effect of spinning speed and air gap distance on fibers dimensions has been summarized in Table 3. It can be noticed clearly that both inner and outer diameters of the fibers decrease by increasing the air gap and winding speed in accordance with what has been reported in literature [23]. The increase in air gap will allow the die swell to be more pronounced but at the same time, the weight of unsupported fraction of the fiber will increase. The winding speed will suppress the die swell by increasing the elongation force and by decreasing the free fall time for the fiber. During the formation of conventional straight fibers, the spinning force exerted on fiber and acting on the dope solution overcomes the surface tension force of external coagulant which acts in opposite direction. However, if the amount of dope solution poured is very small and the winding speed is reduced, the dope solution will start to float on coagulant due to dominance of surface tension on gravitational and elongation forces (caused due to winding). If the elongation force is very less than the surface tension force, the fibers will start to stick with each other giving rise to the formation of solid waste. The phenomenon has been explained schematically in Figure 4 where $F_{S}, F_{T}$, and $F_{E}$ denote the force due to surface tension of coagulant, tensile force due to weight of the fiber and elongation force inserted by the winder, respectively. In current study, the wavy shaped hollow fiber membranes were regularly obtained by reducing winding speed from 9.8 to $8.6 \mathrm{~m} / \mathrm{min}$ corresponding to condition (d) mentioned in Table 3 for dope extrusion rate of $1 \mathrm{~g} / \mathrm{min}$. Hollow fibers were suddenly vibrated at equilibrium conditions, state of wave pattern presented, was so sensitively observed due to a small quantity of dope extrusion rates and just $340 \mu \mathrm{m}$ of diameter of hollow fibers. Instability effects observed in lumen side of the fiber [25] during fabrication process could be helpful in understanding the exact mechanism of helix wave formation.

The effect of air gap distance on microstructure of fibers formed has been illustrated in Figure $\mathbf{5}$. It can be observed from the figure that air gap distance does not alter the microstructure of the membrane. Under all the air gaps investigated, the relatively dense inner structure surrounded with relatively porous layer has been observed. The observed morphology is in accordance with the trend well acknowledged in the literature that the use of weak non solvent produces relatively smooth structure due to slow rate of demixing while the strong coagulants give rise to more porous structures [26]. In current study, 80/20 NMP/Water (wt 


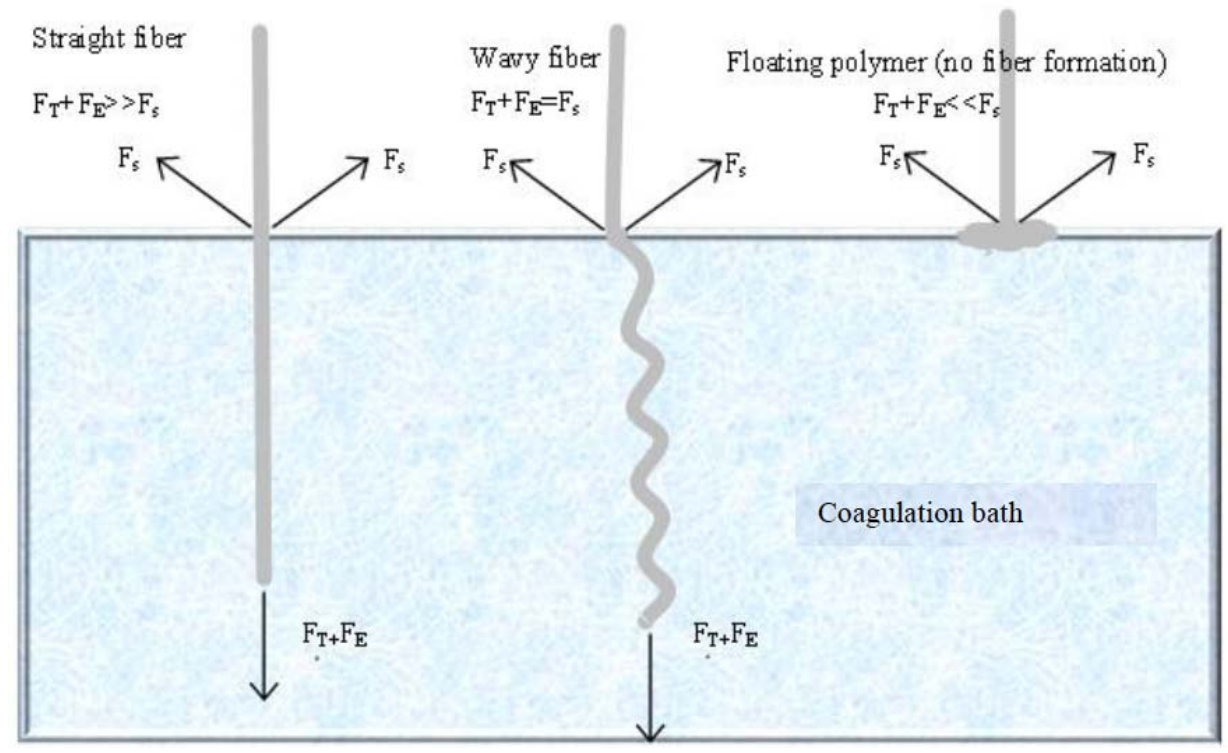

Figure 4: Schematic diagram of forming mechanisms of wavy shape hollow fibers.

Table 3: Experimental Design of Spinning

\begin{tabular}{|c|c|c|c|c|c|c|}
\hline Exp. & $\begin{array}{c}\text { Speed of } \\
\mathbf{S} \text { Spinning } \\
(\mathbf{m} / \mathbf{m i n})\end{array}$ & Spinning & $\begin{array}{c}\text { Outer diameter } \\
(\boldsymbol{\mu m})\end{array}$ & Inner diameter $(\boldsymbol{\mu m})$ & $\begin{array}{c}\text { Air-gap } \\
(\mathbf{c m})\end{array}$ & $\begin{array}{c}\text { OD/ID } \\
\text { ratio }\end{array}$ \\
\hline \hline (a) & 6.5 & free-fall & 560 & 305 & 0 & 1.8 \\
\hline (b) & 6.5 & free-fall & 480 & 260 & 1 & 1.85 \\
\hline (c) & 9.8 & elongation & 320 & 165 & 4 & 1.9 \\
\hline (d) & 8.6 & elongation & 340 & 190 & 4 & 1.8 \\
\hline
\end{tabular}

$\%)$ mixture and pure water used as the inner and outer coagulants serve as the weak and strong non solvent, respectively.

The formation of wavy shaped hollow fiber was sensitive to a several parameters. Viscoelastic properties of polymer dope solution are of fundamental importance in general. In current study, the amount of polymer dope and its density must be very small to ensure the floatation of the dope at the water surface. The drawing speed of the winder should be controlled very precisely, as it will play an important role in dictating the balance between bouncy and sinking forces. The environment should be vibrations free and carefully controlled in order to avoid the disturbance of the equilibrium between the bouncy and downwardacting forces. For a particular process, the surface tension of the coagulant and density and viscosity of dope solution are fixed under constant conditions and the variable of interest are limit to air gap distance, winding speed and polymer extrusion rate. Frequencies, becoming wavy shapes, were observed at $8.6 \mathrm{~m} / \mathrm{min}$ of drawing speeds when dope solution flow rate was held on $1 \mathrm{~g} / \mathrm{min}$. For a given air gap distance of $4 \mathrm{~cm}$ and dope extruding rate of $1 \mathrm{~g} / \mathrm{min}$, the winding speeds exceeding than $8.6 \mathrm{~m} / \mathrm{min}$ generate conventional straight hollow fibers while the speeds lower than this value causes the extruded dope strands to stick with each other to form solid waste.

\subsection{Wavy Shape Formation-Molecular Interpreta- tion}

The mechanism of wavy shaped fiber formation can be explained on the basis of residual stresses present into the fiber due to asymmetric coagulation. Residual stress is a process-induced stress, frozen in a polymeric structure during its fabrication. It can be either flow-induced or thermal-induced. Unstressed, long-chain polymer molecules tend to conform to a 


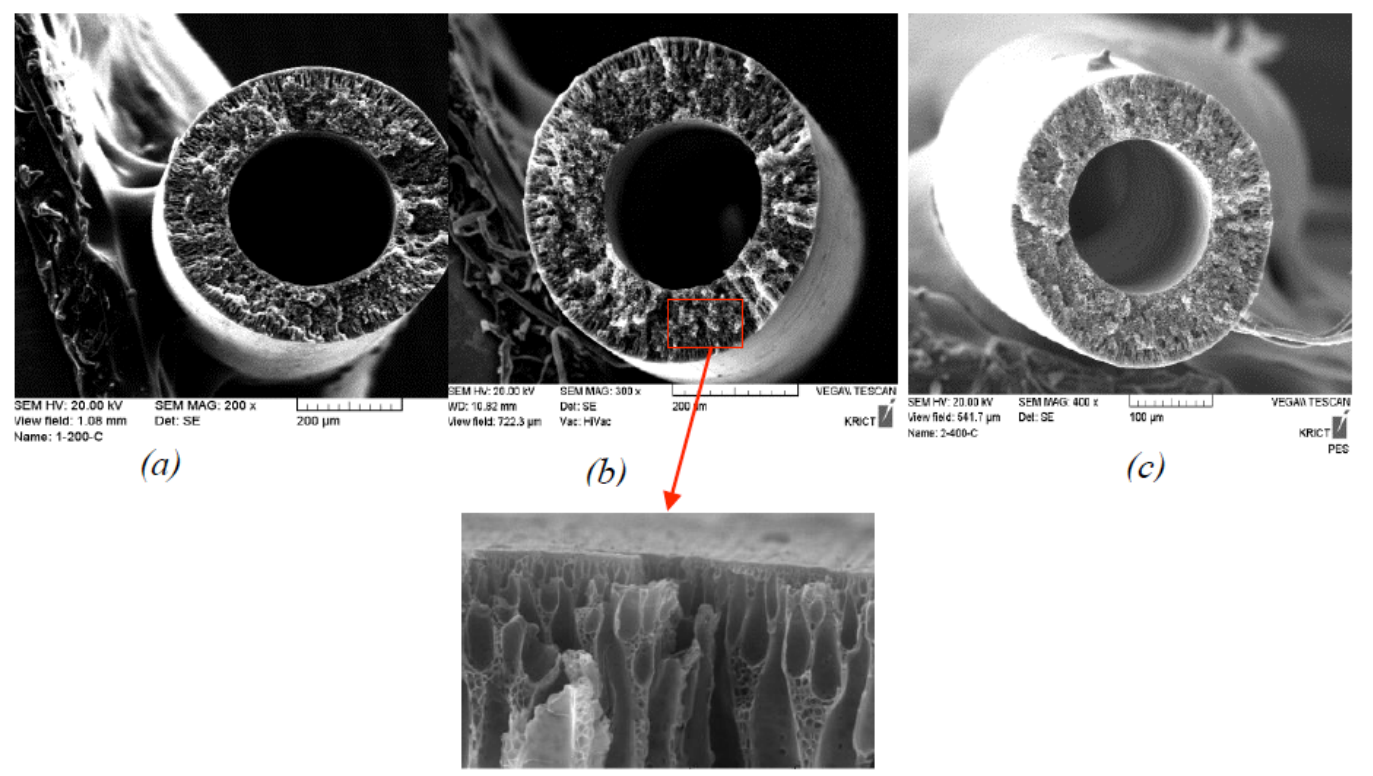

(d)

$\begin{array}{lll}\text { (a) Free-fall, Wet spinning } & \text { (b) Free-fall, Dry-wet } & \text { (c) Elongation, Dry-wet } \\ & \text { spinning } & \text { spinning } \\ \text { (air-gap : Ocm) } & \text { (air-gap : } 1 \mathrm{~cm} \text { ) } & \text { (air-gap : } 4 \mathrm{~cm} \text { ) } \\ \text { Magnification : } 200 x & \text { Magnification : 300x } & \text { Magnifion : 400x } \\ \text { (d) Outer periphery of the } & \\ \text { fiber } & \end{array}$

Figure 5: SEM image of cross sections of hollow fibers prepared under varied conditions of air gap distances and with or without elongation.

random-coil state of equilibrium at temperatures higher than the melt temperature or in solution form. During processing through a spinneret or die, molecules orient in the direction of flow, as the polymer dope is sheared and elongated. If solidification occurs before the polymer molecules are fully relaxed to their state of equilibrium, molecular orientation is locked within the fabricated fiber. In current study, the conditions under which fiber starts to float on coagulant solution give rise to asymmetrical quenching/cooling across the crosssection of the fiber. The section of the fiber in contact with the coagulant has more residual stresses than the other one where the cooling/ phase separation is retarded. When the fiber is drawn through the coagulant, the phase separation takes place in the rest of the fiber too but due to different stress across the cross section of the fiber, it turns into wavy pattern. These observations have been mentioned in literature about polymeric filaments [27]. The study carried out by A. Demsar [28] has also shown that in order to obtain crimp structure, after asymmetric conditions applied, the fibers must be stretched as the bilateral structure of the formed fiber respond differently to an applied stress due to different shrinkage characteristics. The net of the surface tension of the water used as coagulant and winding force provide the force necessary to make crimpy fibers in current study.

\section{CONCLUSION}

Novel process to synthesize helix-wave hollow fiber membrane has been addressed. The fibers have been prepared by the simple non solvent induced phase separation process with asymmetric coagulation followed by drawing of the fibers with particular force dictated by the difference in drawing force and the surface tension of coagulant. The formation of helix wave configuration is influenced by parameters including solution density, surface tension of the coagulant and drawing speed of the winder. It has been postulated that the specific configuration achieved is due to asymmetric cooling of the fiber that induces high residual stresses inside the portion of the fiber that comes in contact first with the liquidduring floatation over the coagulant. Upon drawing through the coagulant bath, two sections of fiber located at the same periphery respond differently, resulting into the observed crimps. The produced fibers can find potential applications in conventional and emerging membrane processes to reduce polarization effects. 


\section{REFERENCES}

[1] Drioli E, Brunetti A, Pro D, Barbieri G. Green Chemistry Process intensi fi cation strategies and membrane engineering. Green Chem 2012; 14: 1561-1572.

http://dx.doi.org/10.1039/c2gc16668b

[2] Jaffrin MY. Hydrodynamic Techniques to Enhance Membrane Filtration. Annu Rev Fluid Mech 2012; 44: 77-96. http://www.annualreviews.org/doi/abs/10.1146/annurev-fluid120710-101112

[3] Scott K, Mahmood AJ, Jachuck RJ, Hu B. Intensified membrane filtration with corrugated membranes. J Memb Sci 2000; 173: 1-16.

http://dx.doi.org/10.1016/S0376-7388(00)00327-6

[4] Moulin P, Rouch JC, Serra C, Clifton MJ, Aptel P. Mass transfer improvement by secondary flows: Dean vortices in coiled tubular membranes. J Memb Sci 1996; 114(2): 235244. http://dx.doi.org/10.1016/0376-7388(95)00323-1

[5] Teoh MM, Bonyadi S, Chung T. Investigation of different hollow fiber module designs for flux enhancement in the membrane distillation process. J Memb Sci 2008; 311: 371379 .

http://dx.doi.org/10.1016/i.memsci.2007.12.054

[6] Mallubhotla H, Hoffmann S, Schmidt M, Vente J, Belfort G. "Flux enhancement during dean vortex tubular membrane nano $\circledast$ Itration. J Memb Sci 1998; 141: 183-195. http://dx.doi.org/10.1016/S0376-7388(97)00302-5

[7] Ali A, Macedonio F, Drioli E, Aljil S, Alharbi OA. Experimental and theoretical evaluation of temperature polarization phenomenon in direct contact membrane distillation. Chem Eng Res Des 2013; 91(10): 1966-1977. http://dx.doi.org/10.1016/j.cherd.2013.06.030

[8] Martínez JMR-ML. Characterization of membrane distillation modules and analysis of mass flux enhancement by channel spacers. J Memb Sci 2006; 274: 123-137.

http://dx.doi.org/10.1016/j.memsci.2005.07.045

[9] Chernyshov MN, Meindersma GW, De Haan AB. Comparison of spacers for temperature polarization reduction in air gap membrane distillation. Desalination 2005; 183: 363374.

\section{http://dx.doi.org/10.1016/i.desal.2005.04.029}

[10] Martinez-Diez, Vazquez-Gonzalez, Florido-Diaz. Study of membrane distillation using channel spacers. J Memb Sci 1998; 144: 45-56.

http://dx.doi.org/10.1016/S0376-7388(98)00024-6

[11] Phattaranawik J, Jiraratananon R, Fane A. Heat transport and membrane distillation coefficients in direct contact membrane distillation. J Memb Sci 2003; 212(1-2): 177-193. http://dx.doi.org/10.1016/S0376-7388(02)00498-2

[12] Xing Yang AGF, $\mathrm{Yu} \mathrm{H}$, Wang $\mathrm{R}$. Optimization of microstructured hollow fiber design for membrane distillation applications using CFD modeling. J Memb Sci 2012; 421422: 258-270.

http://dx.doi.org/10.1016/j.memsci.2012.07.022

[13] Yang $X$, Wang R, Fane AG. Novel designs for improving the performance of hollow fiber membrane distillation modules. $\mathrm{J}$ Memb Sci 2011; 384(1-2): 52-62. http://www.sciencedirect. com/science/article/pii/S0376738811006788

[14] Bikson B, Salvatore G. Methods for gas separation using helically wound hollow fibers permeable membrane cartridge.
US Patent 48819551989. http://www.google.com.py/patents/ EP0359175B1?cl=en

[15] G. T. Leypoldt JK, Cheung AK, Agodoa LY, Daugirdas JT and K. PR, "Hemodialyzer mass transfer-area coefficients for urea increase at high dialysate flow rates. The Hemodialysis (HEMO) Study. Kidney Int 1997; 51: 1913-1917. http://www.ncbi.nlm.nih.gov/pubmed/9186896

[16] Ronco C, Brendolan A, Crepaldi C, Rodighiero M, Scabardi M. Blood and Dialysate Flow Distributions in Hollow-Fiber Hemodialyzers Analyzed by Computerized Helical Scanning Technique. J Am Scoiety Nephrol 2002; 13: 53-61. http://www.ncbi.nlm.nih.gov/pubmed/11792763

[17] Akai KIS. Technical Characterization of Dialysis Fluid Flow of Newly Developed Dialyzers Using Mass Transfer Correlation. ASAIO 2009; pp. 231-235. http://www.ncbi.nlm.nih.gov/ pubmed/19357496

[18] Tatebe K, Yamazaki M. Oxygenator using porous hollow fiber membrane. US 54893821996. http://www.google.com/ patents/US6495101

[19] Taniguchi T, Suga N, Otoyo T. United States Patent, Method for purifying aqueous suspension. 6495041 B22002.

[20] Osabe M, Nakamatsu O, Sugaya H. Hollow fiber membranes and hollow fiber membrane modules having the same included therein. 0000936 A12010. http://www.freepatentsonline.com/y2010/0000936.html

[21] Akai KIS. Technical Characterization of Dialysis Fluid Flow of Newly Developed Dialyzers Using Mass Transfer Correlation Equations. ASAIO 2009; pp. 231-235. http://www.ncbi.nlm. nih.gov/pubmed/19357496

[22] Yang $\mathrm{X}, \mathrm{Yu} \mathrm{H}$, Wang $\mathrm{R}$, Fane AG. Optimization of microstructured hollow fiber design for membrane distillation applications using CFD modeling. J Memb Sci 2012; 421422: $258-270$. http://dx.doi.org/10.1016/j.memsci.2012.07.022

[23] Peng N, Widjojo N, Sukitpaneenit P, May M, Lipscomb GG Chung T, Lai J. Evolution of polymeric hollow fibers as sustainable technologies: Past, present, and future. Prog Polym Sci 2012; 37(10): 1401-1424. http://dx.doi.org/10.1016/j.progpolymsci.2012.01.001

[24] Monisa MD. A Simplified Nonlinear Generalized Maxwell Model for Predicting the Time Dependent Behavior of Viscoelastic Materials. World J Mech 2011; 1: 158-167. http://dx.doi.org/10.4236/wjm.2011.13021

[25] Bonyadi S, Chung TS, Krantz WB. Investigation of corrugation phenomenon in the inner contour of hollow fibers during the non-solvent induced phase-separation process. J Memb Sci 2007; 299: 200-210. http://dx.doi.org/10.1016/j.memsci.2007.04.045

[26] Drioli E, Ali A, Simone S, Macedonio F, AL-Jlil SA, A Shabonah FS, Al-Romaih HS, Al-Harbi O, Figoli A, Criscuoli A. Novel PVDF hollow fiber membranes for vacuum and direct contact membrane distillation applications. Sep Purif Technol 2013; 115: 27-38.

http://dx.doi.org/10.1016/j.seppur.2013.04.040

[27] Christopher C. Crimped melt spun copolymer filaments. US Patent 5,427,8451995. http://www.google.co.in/patents/ US5427845

[28] Andrej Demsar FS. Crimped polypropylene yarns. Kovine, Zlitine, Tehnol 1999; 33(6): 523-526. http://www.worldcat. org/title/curling-phenomenon-of-polypropyleneyarns/oclc/451177654 